\title{
Failure Analysis of HP40 Steel Tubes utilized in Steam Reformer Units of Petroleum Refinery Plants
}

\author{
Eduardo Perez-Badillo ${ }^{a}$, Dario A. Sigala-Garcia ${ }^{a}$, Diego Rivas-Lopezz, Héctor J. Dorantes-Rosales ${ }^{a}$, \\ Jorge L. Gonzalez-Velazquez ${ }^{a}$, Maribel L. Saucedo-Muñoz ${ }^{a}$,Victor M. Lopez-Hirata ${ }^{a}$ * (]) \\ anstituto Politécnico Nacional, Escuela Superior de Ingeniería Química e Industrias Extractivas \\ (ESIQIE), Ciudad de México, México
}

Received: December 30, 2019; Revised: April 04, 2020; Accepted: May 12, 2020

\begin{abstract}
This work is focused on the failure analysis of a HP40 steel tube used in steam reformer units, which was operated at about $850{ }^{\circ} \mathrm{C}$ for $100000 \mathrm{~h}$. The failure analysis was conducted experimentally and numerically using the Thermo-Calc software. The main results indicated that the failed tube presented slightly different contents of $\mathrm{Ni}$ and $\mathrm{Cr}$ from the nominal ones, which originated the absence of the interdendritic eutectic microconstituent, composed of austenite and $\mathrm{M}_{7} \mathrm{C}_{3}$ carbides. This fact was also corroborated by Thermo-Calc results. This absence of eutectic facilitates the crack propagation on the dendritic zones and then the trangranular brittle fracture propagation through the austenite dendritic zones.
\end{abstract}

Keywords: As-Cast HP40 steel, tubes, microstructure, failure.

\section{Introduction}

The steam reformer unit is a fundamental equipment in many processes of the petroleum refinery plants. This unit is composed of a wide variety of vertically oriented tubes $^{1}$. A mixture of methane and steam usually pass through the oxide catalyst in the steam reformer to obtain a mixture of hydrogen, carbon monoxide, carbon dioxide and water. The combination of high temperature, carbon oxide atmosphere and moderate tensile stresses causes that the damage in these components occurs mainly by the presence of creep, microstructural degradation and metal dusting ${ }^{1}$. These components operate at temperatures of approximately $850{ }^{\circ} \mathrm{C}$ and internal pressures between 1 and $3.5 \mathrm{MPa}$, and its service life is expected to be about $100,000 \mathrm{~h}^{2-6}$. This type of components is usually fabricated with heat resistant austenitic stainless steel, like the HP40 steel (25Cr-35Ni steel), which has excellent creep strength, and good resistance to carburization and oxidation ${ }^{1-6}$.

The HP40 steel is used in the as-cast condition, and its high content of $\mathrm{Cr}$ and $\mathrm{Ni}$ promotes a microstructure composed of a net of primary eutectic precipitates $\left(\gamma+\mathrm{M}_{7} \mathrm{C}_{3}\right)$ located in the dendritic boundaries of an fcc $\gamma$ austenitic phase $\mathrm{e}^{3-8}$. These $\mathrm{Cr}$-rich $\mathrm{M}_{7} \mathrm{C}_{3}$ carbides are known as primary carbides and they perform an important role on the prevention of sliding of the austenite grain boundaries at high temperatures ${ }^{8-12}$ Besides, $\mathrm{Nb}$-rich MC carbides can be formed during the solidification process, which also contributes to improve its mechanical strength. The secondary fine precipitation of $\mathrm{Cr}$-rich carbides, $\mathrm{M}_{23} \mathrm{C}_{6}$ with cubic morphology, restrict the movement of the dislocations, making of this alloy an excellent option to these operating conditions ${ }^{13-15}$. The volume fraction of this precipitation has been reported ${ }^{14}$ to increase with carbon content of steel.

*e-mail: vlopezhi@prodigy.net.mx
This precipitation also contributes to increase the wear resistance of these alloys ${ }^{8-15}$.

An optimum control of the chemical composition of the as-cast alloy is important to reach the required mechanical properties of tubes used in the steam reformer. Thus, a slight deviation in the chemical composition may alter the microstructure promoting a deterioration in its mechanical properties, which could lead to unexpected failures during its service operation.

Recently, Thermo-Calc (TC) software has been applied to analyze ${ }^{16,17}$ the stability of phases in both equilibrium and non-equilibrium conditions for multicomponent alloys. Furthermore, TC-PRISMA ${ }^{16}$ has permitted to analyze the growth kinetics of different precipitates either, during continuous cooling or isothermal aging. These calculated results are a good alternative to study the microstructural evolution of the multicomponent alloys used for the fabrication of industrial components.

Therefore, the aim of this work is to analyze experimentally and numerically the effect of chemical composition on the microstructure evolution and its corresponding mechanical performance for two different sections, one of them extracted from a failed HP40 steel tube, with slight difference in the chemical composition from the nominal one.

\section{Materials and Experimental Details}

\subsection{Sampling and sectioning}

Figure 1 shows a section of the failed GX45NiCrNbTi steel tube with a nominal diameter and thickness of $21.7 \mathrm{~cm}$ (5 in) and $0.9144 \mathrm{~cm}$ (0.360 in), respectively. This tube operated at about $850^{\circ} \mathrm{C}$ for $100000 \mathrm{~h}$. The tube shows a welded reduction in one of the ends. The failure consists of a fracture, with length of $96.52 \mathrm{~cm}$ (38 in) and a fish-mouth like aperture 
of $25.4 \mathrm{~cm}$ (10 in), propagated in the longitudinal direction. A secondary circumferential fracture can be observed in the weld joint of the tube reduction, as shown in Figure 1.

The tube was sectioned in two segments, as shown in Figure 2. These were designated as follows: A1 the fractured element of about $36 \mathrm{~cm}$ length next to edge of the flaw, as shown in Figure 2a, and A2 the element, exposed to the highest temperature, without any presence of crack propagation with a length of approximately $10 \mathrm{~cm}$, as shown in Figure $2 \mathrm{~b}$.

\subsection{Experimental details}

The chemical composition of A1 and A2 specimens is shown in Table 1, and it was determined by atomic absorption spectroscopy (AAS). The nominal chemical composition

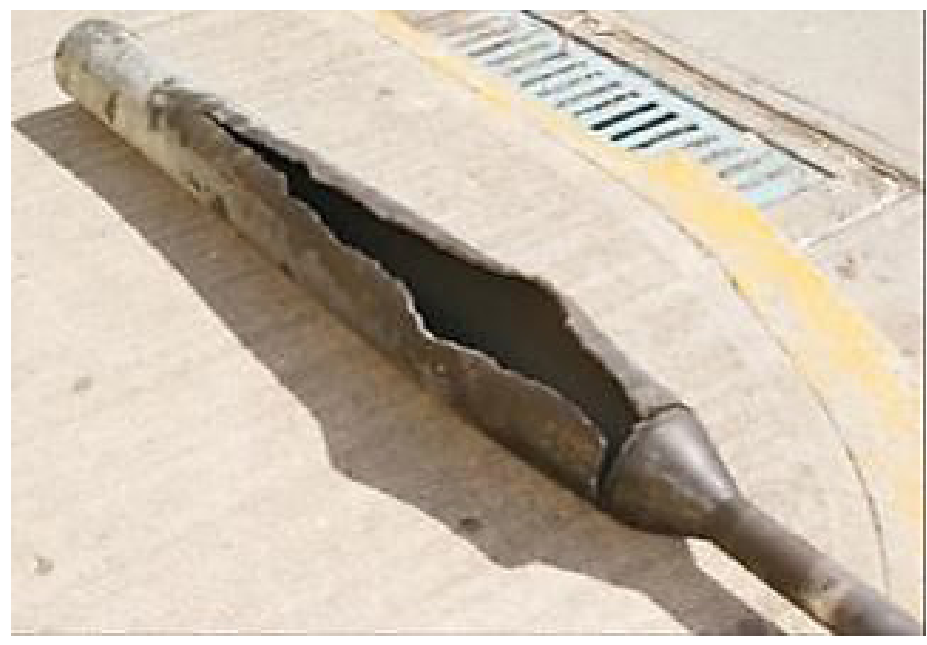

Figure 1. Perspective view of the section of tube failed.

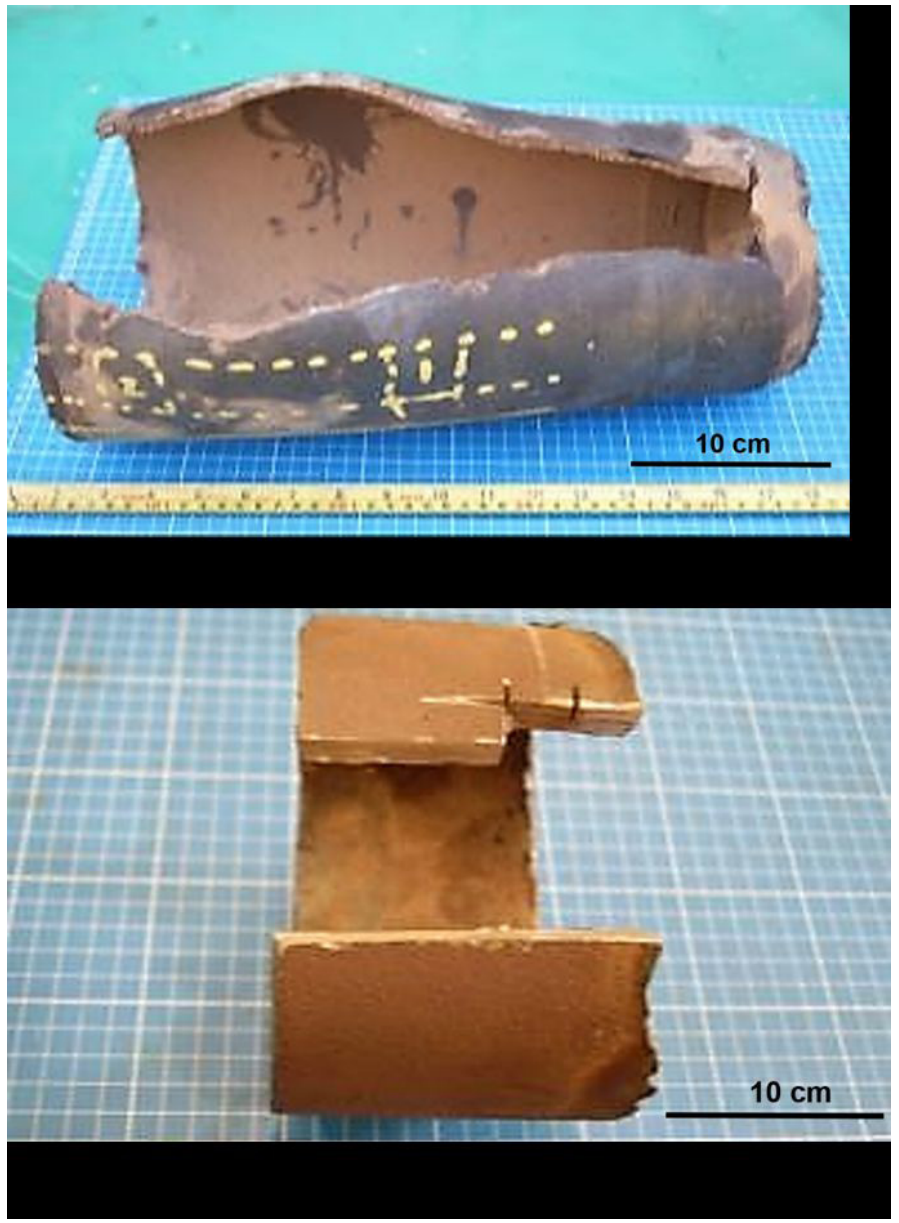

Figure 2. Location of as-received (a) A1 and (b) A2 specimens. 
corresponding to the ASTM A297 standard ${ }^{18}$ is also shown for comparison reason. That is, it can be noted that the chemical composition of A1 specimen presents lower content of $\mathrm{Ni}$ and higher content of $\mathrm{Cr}$ in comparison to those of the nominal composition. In contrast, the chemical composition for A2 specimen is in the composition range expected for this type of steel, according to the ASTM standard ${ }^{18}$. The microstructural analysis of A1 and A2 specimens was performed to compare the initial microstructural of the longitudinal, transversal and the external surfaces for both A1 and A2 specimens. All specimens were metallographically prepared, and then etched with Kalling reagent $(290 \mathrm{ml}$

Table 1. ASTM standard A297 nominal chemical composition of the HP40 steel, compared to those of the A1 and A2 specimens.

\begin{tabular}{cccc}
\hline Element & ASTM A297 & A1 & A2 \\
\hline C wt. \% & $0.35-0.75$ & 0.45 & 0.45 \\
\hline Mn wt. \% & $\max .1 .5$ & 0.8 & 0.73 \\
\hline Si wt. \% & max. 2.0 & 1.32 & 1.11 \\
\hline Nb wt. \% & 1.25 & 1.24 & 1.27 \\
\hline Ti wt. \% & 0.3 & 0.16 & 0.13 \\
\hline Cr wt. \% & $24-28$ & 29.97 & 27.89 \\
\hline Ni wt. \% & $33-37$ & 31.37 & 33.18 \\
\hline
\end{tabular}

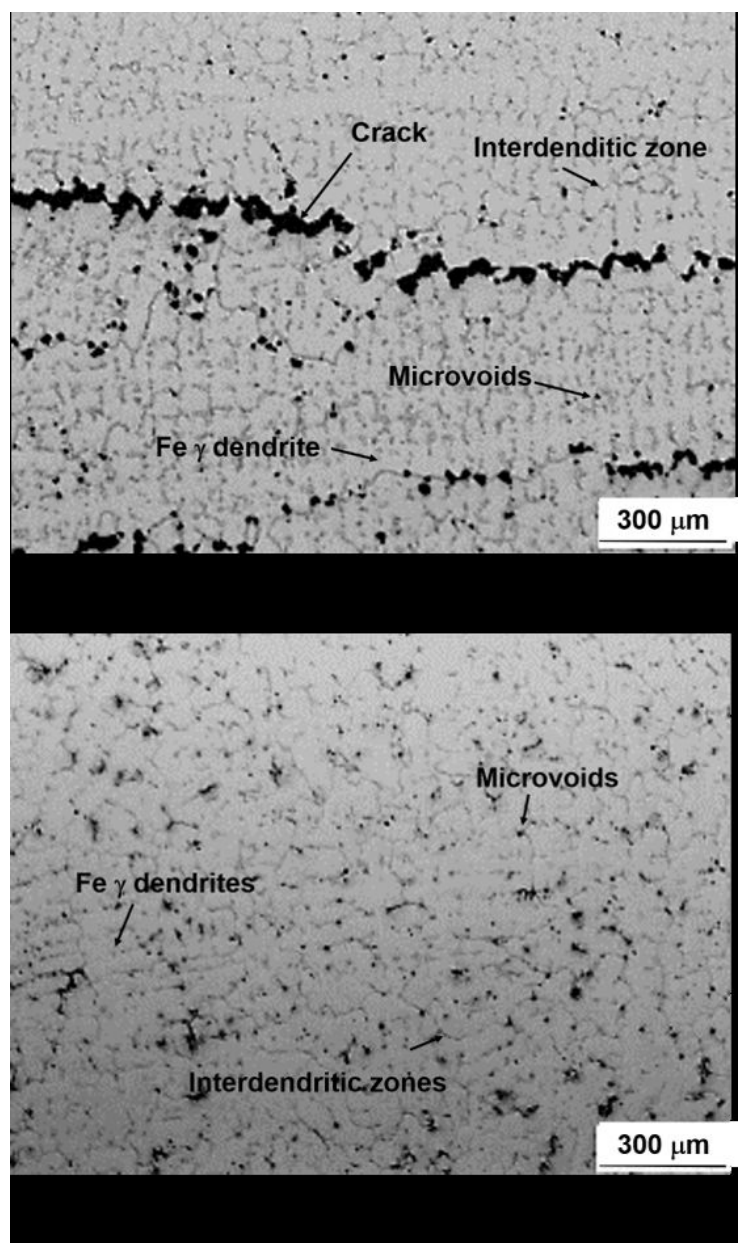

Figure 3. Microstructure of the longitudinal surface for the as-received (a) A1 and (b) A2 specimens. ethanol, $100 \mathrm{ml} \mathrm{HCl}$ and $5 \mathrm{~g} \mathrm{CuCl}_{2}$ ) to be observed with a light microscope. To regenerate the original as-cast microstructure, both $\mathrm{A} 1$ and $\mathrm{A} 2$ specimens were remelted three times in order to homogenize the chemical composition using a Mini-Arc furnace MAM-1 Edmund Bühler GmbH under an argon atmosphere. All specimens were analyzed with scanning electron microscope (SEM) equipped with Energy dispersive X-ray spectroscopy, EDX, to determine the distribution of chemical elements in the A1 and A2 specimens. Some specimens were also examined by X-ray diffraction (XRD) using monochromated $\mathrm{Cu} \mathrm{K} \alpha$ radiation. Brinell hardness and Vickers hardness tests were pursued for all specimens using loads of $3000 \mathrm{~kg}_{\mathrm{f}}$ and $200 \mathrm{~g}_{\mathrm{f}}$ loads, respectively, for $10 \mathrm{~s}$, according to the standard procedure described in the E10 and E92 ASTM standards ${ }^{19,20}$.

\subsection{Numerical methodology}

Thermo-Calc analysis was pursued using the version 2019a and the TCFe7.tdb data base ${ }^{21}$. The non-equilibrium phases were studied using the Scheil module of this software, which is based on the Guiliver-Scheil equations ${ }^{17}$, which are used to study the non-equilibrium solidification process of alloys. The input data were the chemical composition and temperature.

\section{Results and Discussion}

\subsection{Microstructure characterization of the as-received component}

The light microscope microstructures for the transversal surface of the as-received A1 and A2 specimens are shown in Figures $3 \mathrm{a}$ and $\mathrm{b}$, respectively. Both A1 and A2 specimens present a dendritic structure composed of austenite dendrites and interdendritic regions, which shows the presence of small pores or microvoids. It is interesting to notice that some of them are interconnected in the case of A1 specimen. The crack propagation of A1 specimen takes place along the interdendritic zones. Additionally, similar characteristics were also observed for longitudinal and external surfaces of both specimens. Figures $4 \mathrm{a}$ and $\mathrm{b}$ show the SEM micrographs corresponding to the A1 specimen in the as-polished condition and after chemical etching, respectively, at two different magnification levels. Figure 4 a confirms that that the crack propagation occurred intergranularly through the interdendritic zones. Besides, Figure $4 \mathrm{~b}$ suggests that the crack propagation proceeds through the matrix and precipitated carbide phases, which will be described in the next paragraph.

SEM micrographs of the longitudinal surface for the as-received A1 and A2 specimens are shown in Figures $5 \mathrm{a}$ and $\mathrm{b}$, respectively. In the case of as-received A1 specimens, it can be clearly noted the presence of dark and bright precipitates dispersed in the austenite matrix. The EDX analysis indicated that the bright and the dark ones correspond to $\mathrm{Nb}$-rich $\mathrm{MC}$ carbide precipitates and Cr-rich $\mathrm{M}_{23} \mathrm{C}_{6}$ carbide precipitates, respectively. A similar microstructure is present in the as-received $\mathrm{A} 2$ specimen; however, the $\mathrm{Cr}$-rich $\mathrm{M}_{7} \mathrm{C}_{3}$ carbide phase shows a eutectic morphology with the austenite phase. 


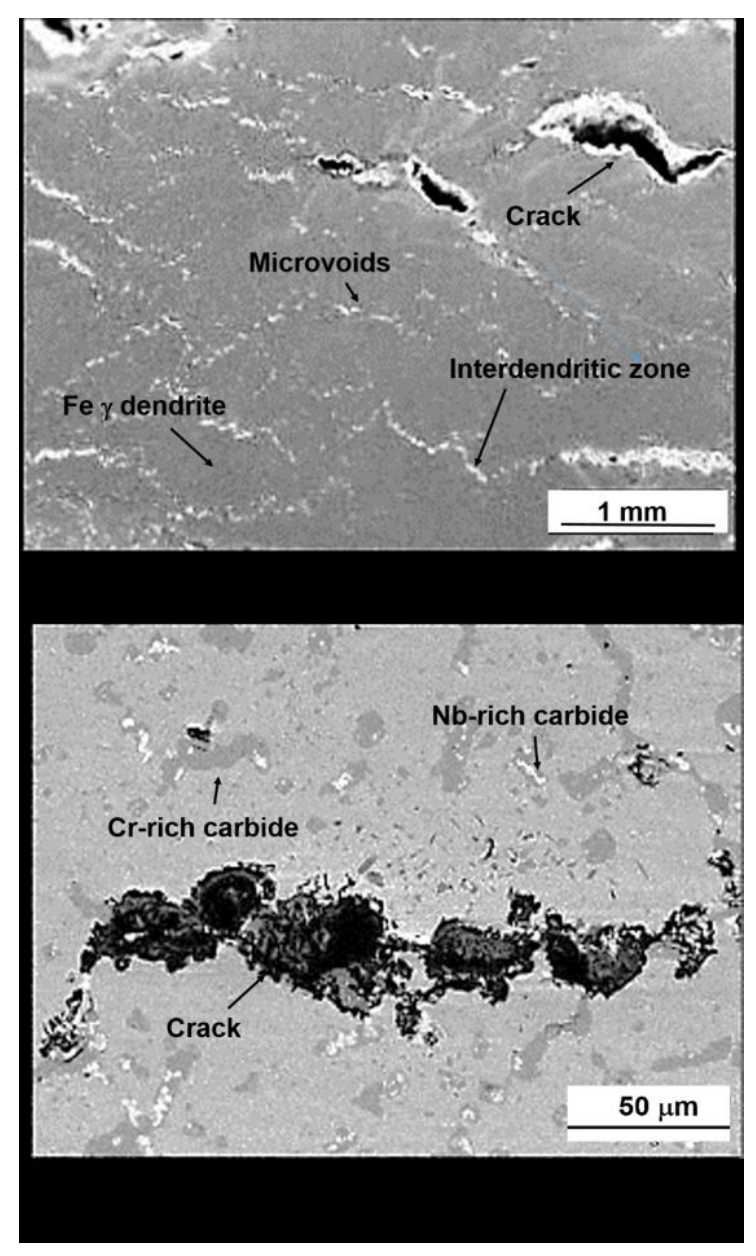

Figure 4. SEM micrographs of the A1 specimen in (a) polished and (b) etched conditions.

\subsection{Thermo-Calc analysis and microstructures}

The Thermo-Calc calculated plot of the amount of all equilibrium phases as a function of temperature is shown in Figures $6 \mathrm{a}$ and $\mathrm{b}$ for the $\mathrm{A} 1$ and $\mathrm{A} 2$ specimens, respectively. In the case of $\mathrm{A} 1$ specimen, the first solid phase to be formed is the austenite and then the $(\mathrm{Nb}, \mathrm{Ti}) \mathrm{C}$ and $\mathrm{M}_{23} \mathrm{C}_{6}$ carbides are solidified. This diagram also suggests that the precipitation of $(\mathrm{Nb}, \mathrm{Ti}) \mathrm{C}$ and $\mathrm{M}_{23} \mathrm{C}_{6}$ carbides from the austenite matrix may occur by isothermal exposing to temperatures lower than $1250^{\circ} \mathrm{C}$. Even more, the formation of ferrite may take place at temperatures lower than $910^{\circ} \mathrm{C}$. On the other hand, the solidification of austenite preceded to that of $(\mathrm{Nb}, \mathrm{Ti}) \mathrm{C}$ for the A2 specimen. To continue, the following eutectic reaction $\mathrm{L} \rightarrow \gamma+\mathrm{M}_{7} \mathrm{C}_{3}$ occurs at about $1280{ }^{\circ} \mathrm{C}$. This plot also indicates that the precipitation of $(\mathrm{Nb}, \mathrm{Ti}) \mathrm{C}$ could take place from the austenite phase at temperatures lower than $1250^{\circ} \mathrm{C}$. In addition to, the precipitation of $\mathrm{M}_{23} \mathrm{C}_{6}$ occurs at temperatures lower than about $1205{ }^{\circ} \mathrm{C}$, as a result of dissolution of the $\mathrm{M}_{7} \mathrm{C}_{3}$ carbide. The $\alpha$ ferrite phase can be also formed at temperatures lower than approximately $730^{\circ} \mathrm{C}$ with lower volume fraction than that of the A1 specimen.

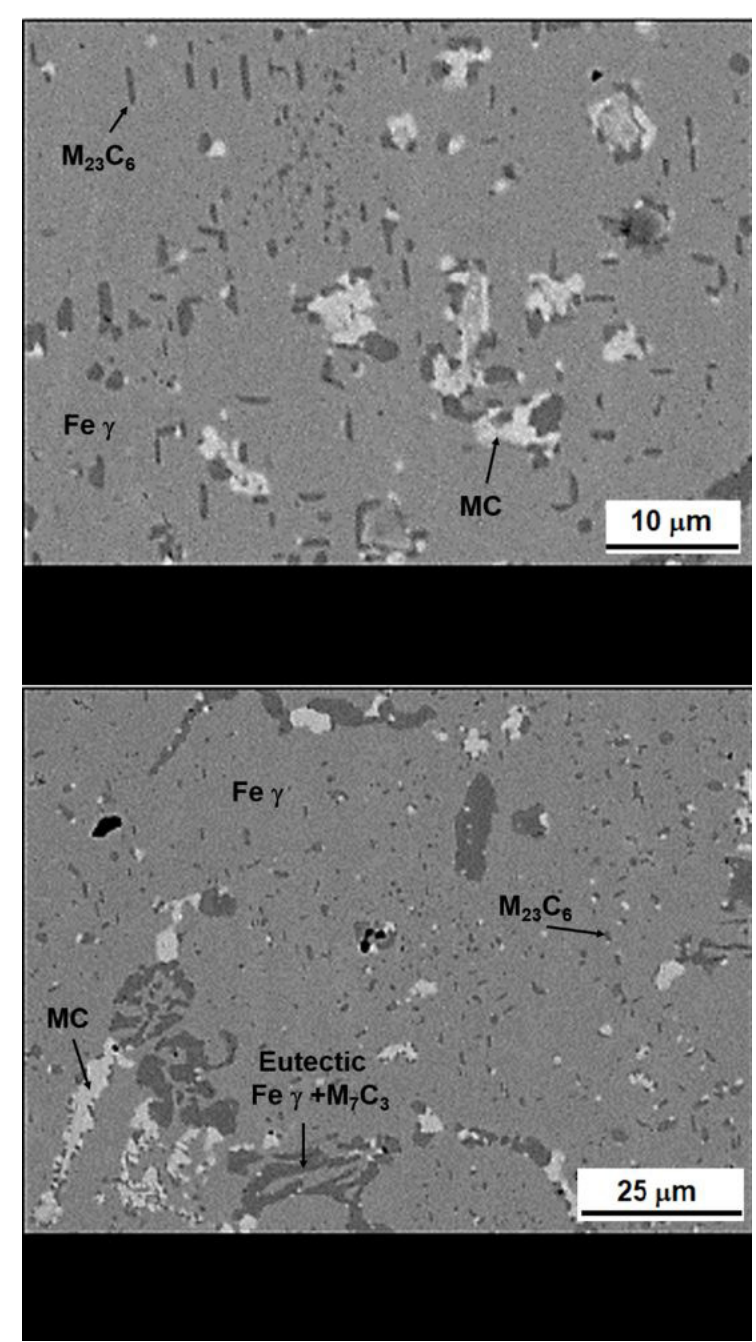

Figure 5. SEM micrographs of the as-received (a) A1 specimen and (b) A2 specimen.

Figures $7 \mathrm{a}$ and $\mathrm{b}$ show the Thermo-Calc calculated plot of temperature versus mole fraction of solid for non-equilibrium conditions of A1 and A2 specimens, respectively, based on the Scheil-Guiliver equations ${ }^{17}$. In the case of both A1 and A2 specimens, it is confirmed that the solidification sequence for non-equilibrium condition is similar to that previously described in Figures $6 a$ and b. That is, there is no eutectic microconstituent, $\gamma+\mathrm{M}_{7} \mathrm{C}_{3}$, for the solidification of A1 specimen. The volume fraction of $\mathrm{M}_{23} \mathrm{C}_{6}$ of this specimen is higher than that of the other one. The precipitation of $\mathrm{M}_{23} \mathrm{C}_{6}$ can take place during non-equilibrium solidification of $\mathrm{A} 2$ specimen. Besides, it can be noted that the $\delta$ ferrite phase is formed during non-equilibrium solidification of both specimens. The volume fraction of this phase is higher for the A1 specimen. A measure of the amount of microsegregation of the as-cast alloy is the separation distance between the equilibrium and non-equilibrium curves of Figure 7. Thus, the A2 specimen has a higher microsegregation, which could cause that the interdendritic liquid reaches the eutectic composition promoting the formation of eutectic microconstituent, $\gamma+\mathrm{M}_{7} \mathrm{C}_{3}$ in comparison to the A1 specimen. 
In order to compare the experimental results with the previously calculated Thermo-Calc results, Figures 8 and $9 \mathrm{a}$ and $\mathrm{b}$ show the SEM micrograph and its corresponding EDX elemental-mapping for the remelted A1 and A2 specimens, respectively. These micrographs confirm that the remelted A1 specimen presents no eutectic constituent, $\mathrm{Fe} \gamma+\mathrm{M} 7 \mathrm{C} 3$. Besides, it can be noted the presence of Cr-rich dark and Nb-rich bright precipitates dispersed in the austenite dendrites. Furthermore, Figure 10a shows the XRD pattern corresponding to the remelted A1 specimen. Three phases are clearly identified to correspond to the X-ray diffraction peaks, and they are the austenite matrix and two types of carbides, $\mathrm{M}_{23} \mathrm{C}_{6}$ and $(\mathrm{Nb}, \mathrm{Ti}) \mathrm{C}$ or $\mathrm{MC}$ carbide type. The $\mathrm{Cr}$-rich $\mathrm{M}_{23} \mathrm{C}_{6}$ carbides show a
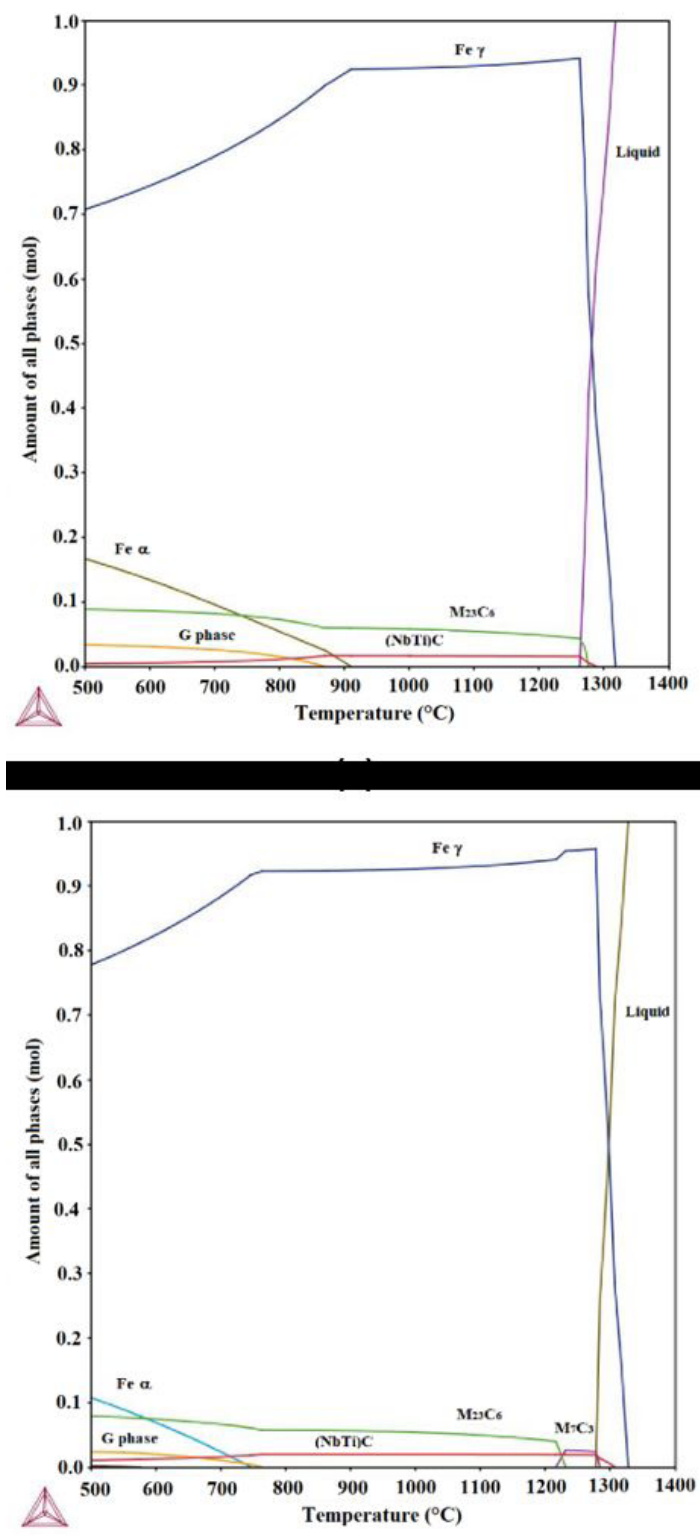

Figure 6. Thermo-Calc calculated plot of amount of all equilibrium phases versus temperature for (a) A1 specimen and (b) A2 specimen. plate morphology, while the morphology of $(\mathrm{Nb}, \mathrm{Ti}) \mathrm{C}$ is irregular. In contrast, the SEM micrograph of the remelted A2 specimen indicates the presence of austenite dendrites and interdendritic MC carbide, as shown in Figure 9b. Besides, the eutectic microconstituent, $\gamma+\mathrm{M}_{7} \mathrm{C}_{3}$ is clearly observed and composed of the austenite and $\mathrm{M}_{7} \mathrm{C}_{3}$ phases. These phases are clearly detected in the XRD pattern of the remelted A1 specimen, as shown in Figure 10b. The EDX analysis of $\mathrm{M}_{7} \mathrm{C}_{3}$ carbides also indicated a Cr-rich carbide for this specimen. Both the calculated and experimental results of the present work are in good agreement with the phase reported for this type of steels in the literature ${ }^{7-15,22-25}$.
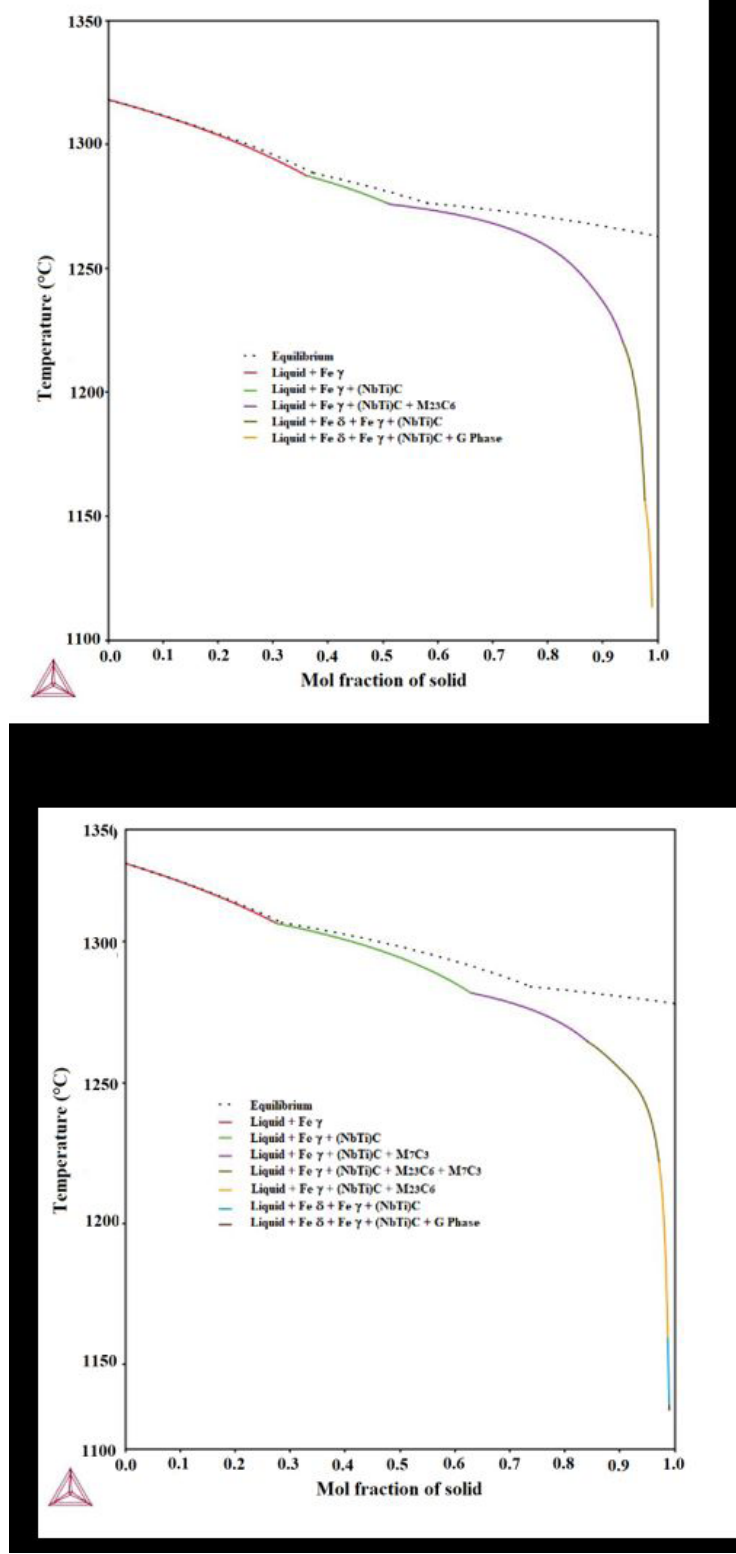

Figure 7. Thermo-Calc calculated plot of non-equilibrium temperature versus mole fraction of solid temperature for (a) A1 specimen and (b) A2 specimen. 


\subsection{Hardness of specimens}

Table 2 shows the Brinell hardness number BHN for the as-received $\mathrm{A} 1$ and $\mathrm{A} 2$ specimens. It can be noted that the average hardness of as-received A 1 specimen is slightly higher than that of the as-received A2 specimen. This difference seems to be attributable to the higher volume fraction of $\mathrm{M}_{23} \mathrm{C}_{6}$ for the former specimen, as-shown in Figure 4a. Another reason for this higher hardness could be
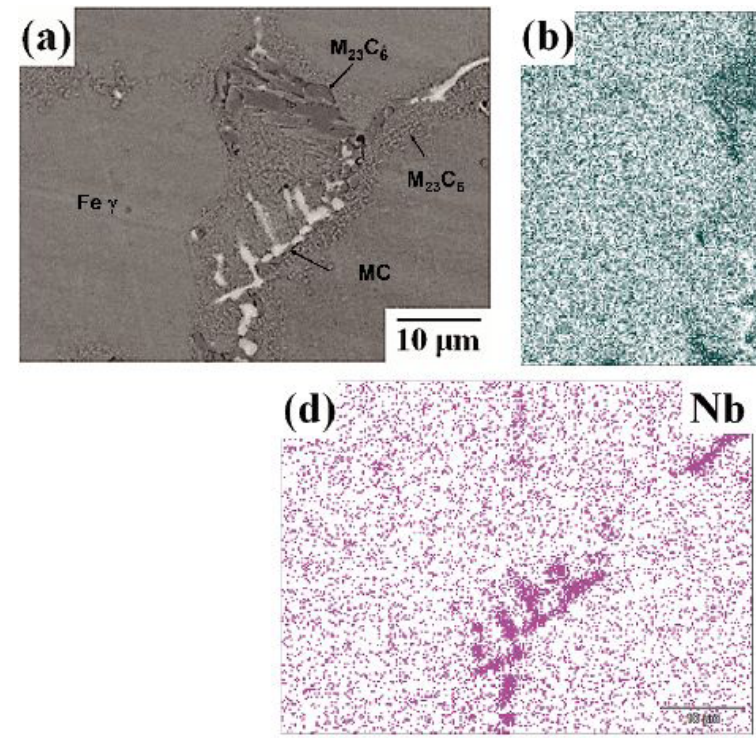
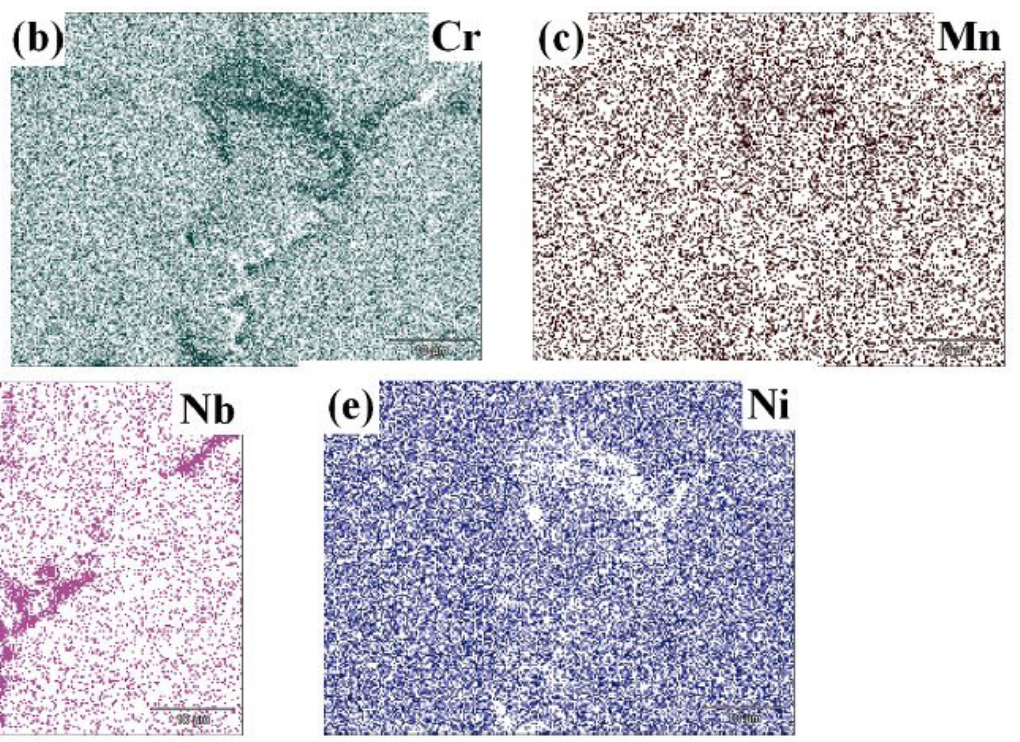

Figure 8. (a) SEM image and the corresponding EDX-SEM elemental mapping images of (b) $\mathrm{Cr}$, (c) Mn, (d) $\mathrm{Nb}$ and (e) $\mathrm{Ni}$ for the remelted A1specimen.

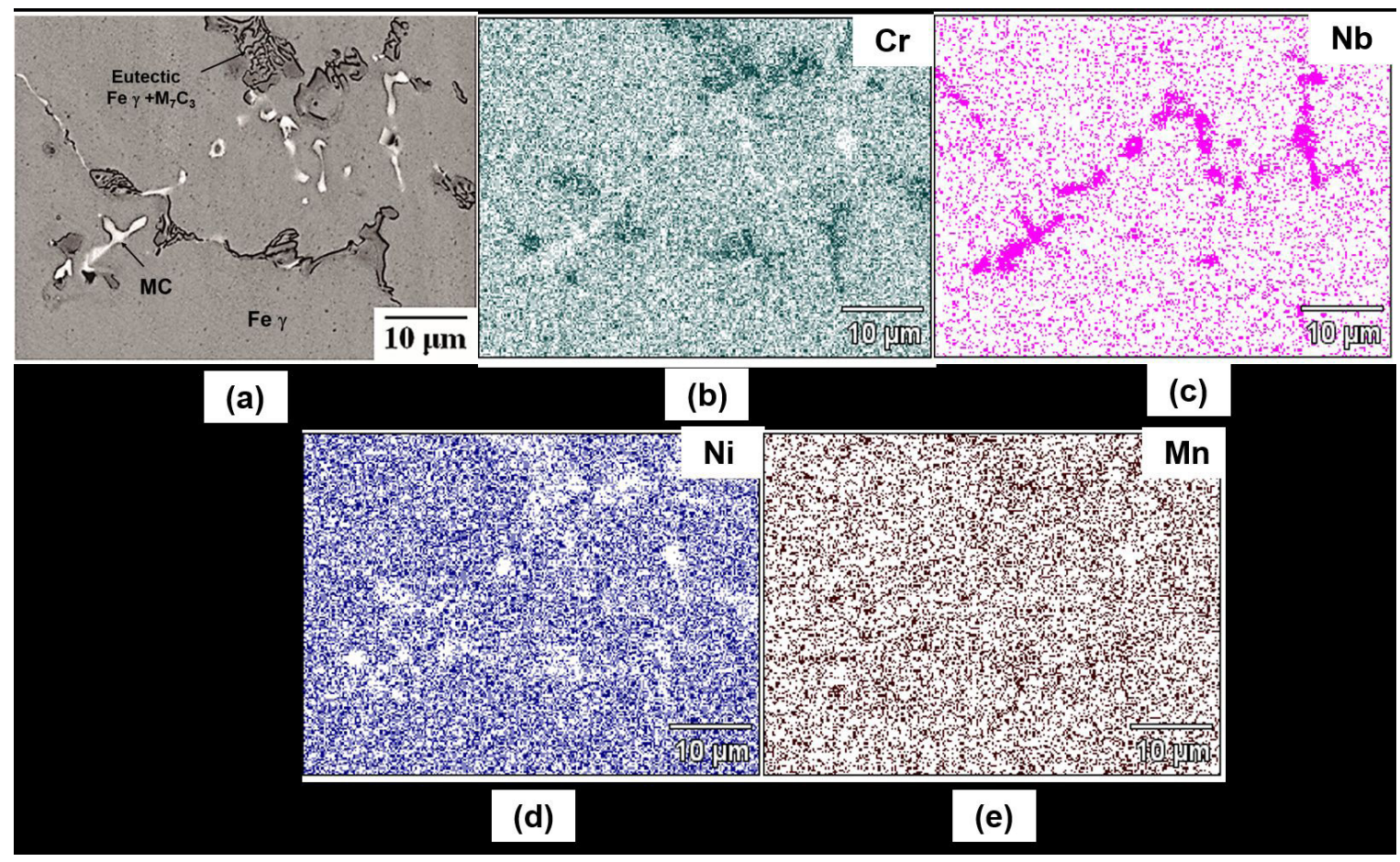

Figure 9. (a) SEM image and the corresponding EDX-SEM elemental mapping images of (b) $\mathrm{Cr}$, (c) Mn, (d) Nb and (e) Ni for the remelted A2 specimen.

Table 2. BHN of the as-received A1 and A2 specimens.

\begin{tabular}{ccccc}
\hline Specimen & Minimum BHN & Maximun BHN & Average BHN & Microhardness VHN \\
\hline A1 & 204.0 & 250.0 & 227.0 & 197 \\
\hline A2 & 202.0 & 207.0 & 204.5 & 175 \\
\hline
\end{tabular}


the highest volume fraction of $\delta$ ferrite for the as-received A1 specimen, which was detected experimentally by the magnetic behavior of this specimen. Nevertheless, the bcc structure of ferrite has a lower toughness than that corresponding to the fcc structure of austenite, which may be also responsible for the deterioration in tube performance. Table 2 also shows the Vickers microhardness corresponding to the matrix phase and it can be noted that the A1 specimen has higher hardness, in good agreement with the previously shown results. The hardness corresponding to the carbides was higher, $325-550 \mathrm{VHN}$, but the data scatter was high because the microhardness determination could also include a contribution from the austenite matrix. The hardness values are consistent with those reported in the literature ${ }^{25}$.

\subsection{Failure mechanism}

Table 3 summarizes the main results of previous sections in order to explain the failure mechanism. These results indicate that the higher $\mathrm{Cr}$ and lower $\mathrm{Ni}$ content of this tube section for as-received $\mathrm{A} 1$ specimen in comparison to the nominal ones, as shown in Table1, promotes the no formation of the eutectic constituent composed of the austenite and $\mathrm{M}_{7} \mathrm{C}_{3}$ carbide decreasing its opposition to the dislocation movement and thus, the interdendritic zones were favorable to the crack propagation. Then,

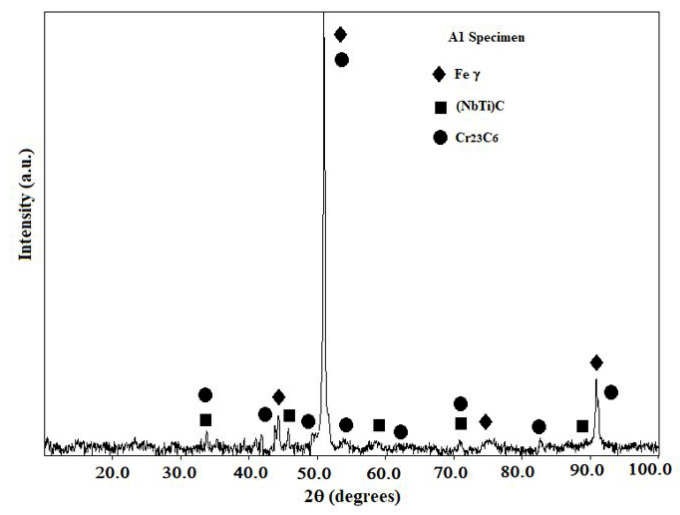

(a)

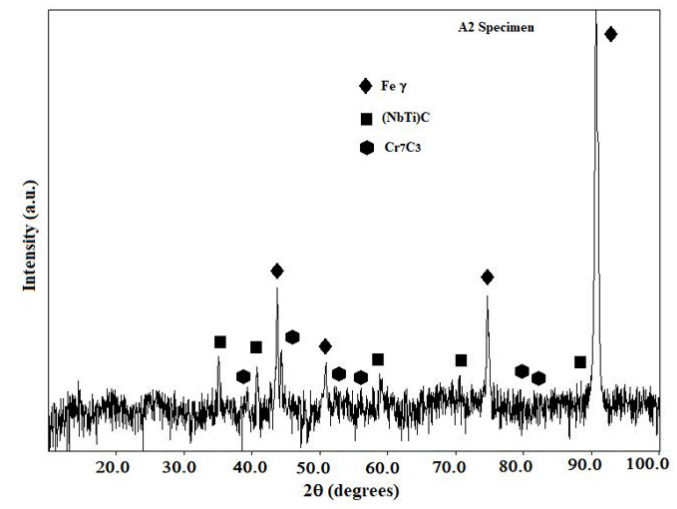

(b)

Figure 10. XRD patterns of the the remelted (a) A1 specimen and (b) A2 specimen. as a result of the creep condition the microvoids are formed and they become interconnected, which favors the crack propagation in the interdendritic regions, the austenite dendritic zones presented the transgranular brittle fracture mode. This fact is consistent with the SEM fractographs of the as-received A1 specimen, as shown in Figures 11a and $\mathrm{b}$. This shows clearly the crack propagation in the interdendritic zones, as well as the transgranular brittle fracture in the austenite. Additionally, the EDX spectrum of the yellow squared area in Figure 11b indicates that the detected chemical elements correspond mainly to the steel. The presence of oxygen is attributed to the oxide formation. Figures 12a-h show the EDX elemental mapping close to a crack for the A1 specimen. The formation of chromium and manganese oxides can be clearly observed in the crack, while there is a depletion of the other elements in the crack. Besides, there is no preferential distribution of elements in the steel. No detection of sulfur or chlorine was found in the crack.

It is important to mention that the micropores, observed in micrographs of Figure 3, may be originated by the void formation during the creep of these tubes at high temperatures and they could be responsible of the crack nucleation ${ }^{26}$.

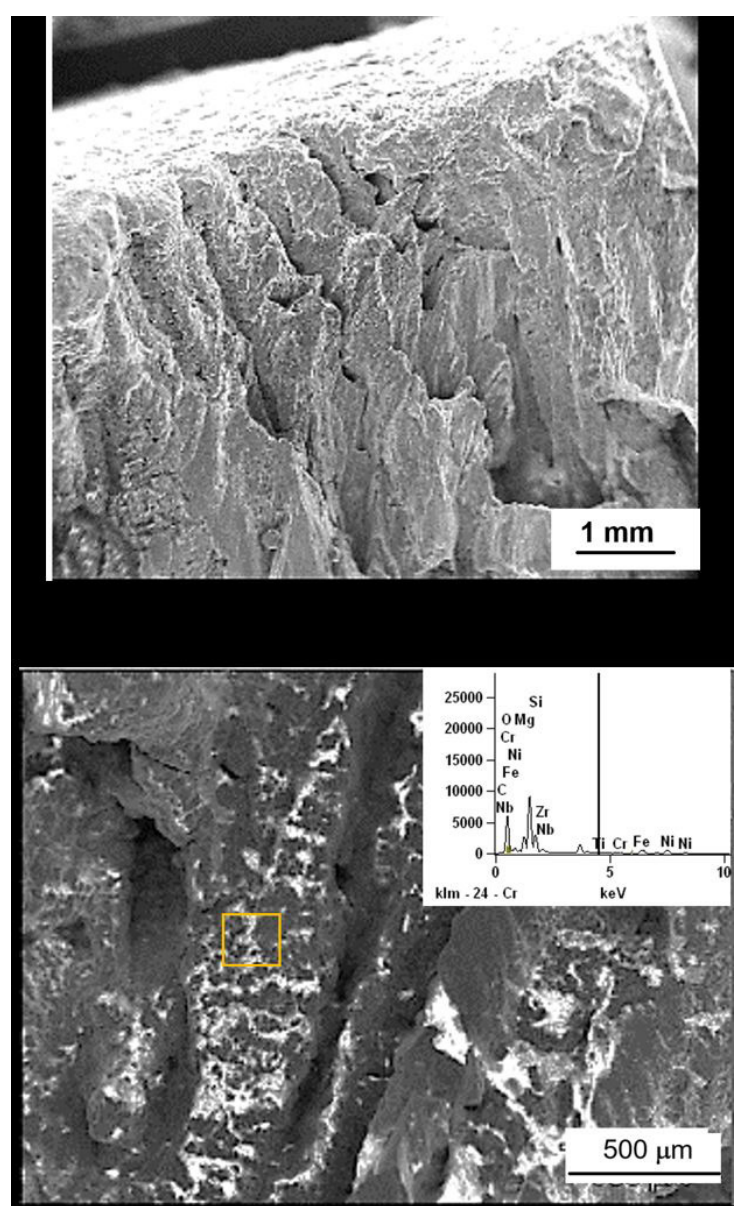

Figure 11. SEM fractographs of the as-received A1 specimen (a) low magnification an (b) high magnification with EDX spectrum. 
Table 3. Summary of failure characteristics.

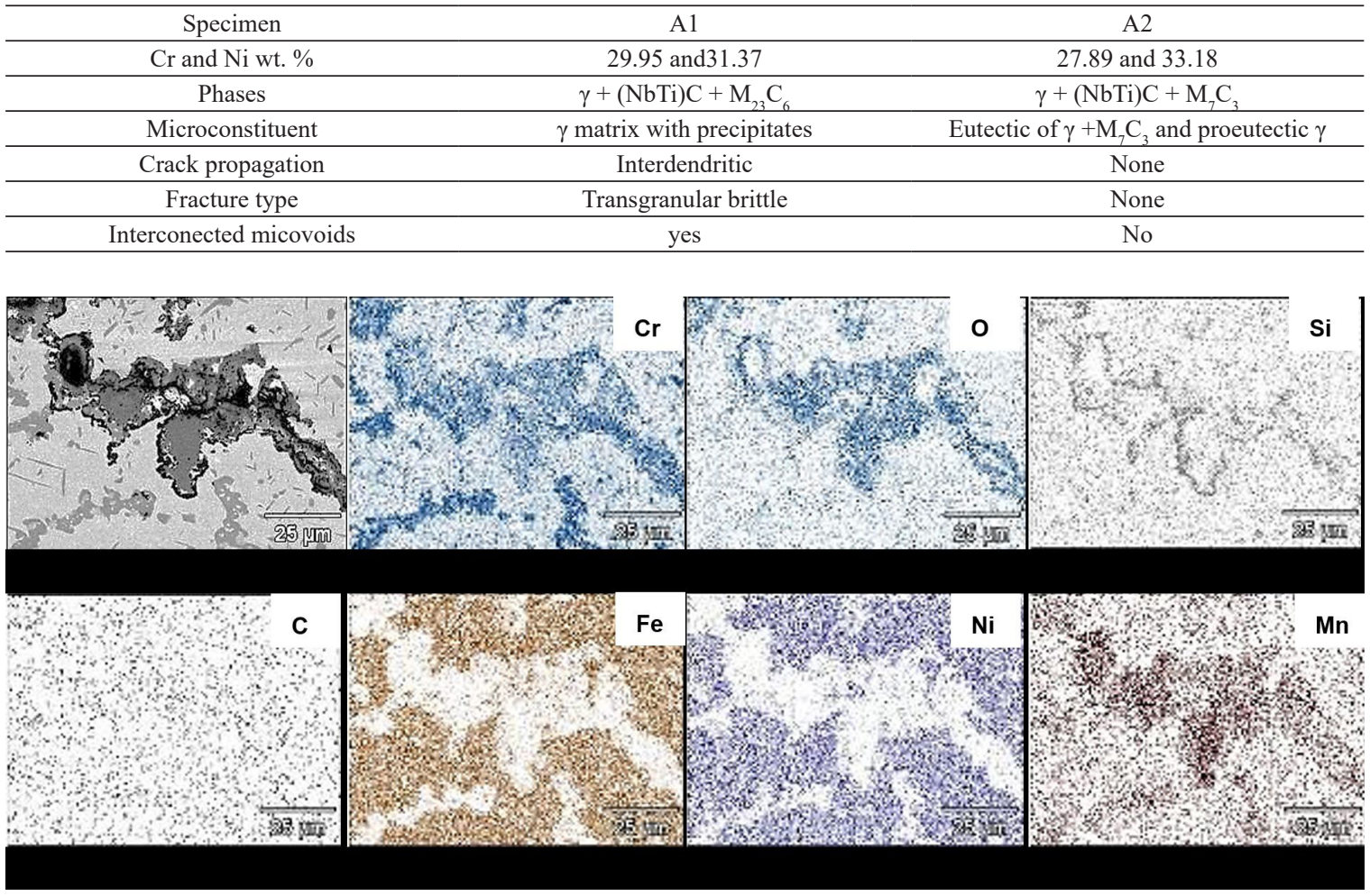

Figure 12. (a) SEM image and the corresponding EDX-SEM elemental mapping images of a crack for the A1specimen (b) Cr, (c) O, (d) Si, (e) C (f) Fe, (g) Ni and (h) Mn.

The presence of ferrite in the A1 specimen may have also contributed to the failure mechanism because of its lower toughness in comparison to that of the austenite. This was not clearly located in the A1 specimen.

In general, it can be stated that the failure mechanism can be attributed to the different chemical composition of the failed zone, related to the nominal one, which may be originated during the casting process of steel tubes.

\section{Conclusions}

A failure analysis of a HP40 steel tube, used in steam reformer units, was conducted experimentally and numerically with Thermo-Calc and the conclusions are:

i) The local difference in $\mathrm{Cr}$ and $\mathrm{Ni}$ contents of the tube promoted the absence of the interdendritic eutectic microconstituent, which facilitated the crack propagation.

ii) This difference also caused the increase in $\delta$ ferrite, which seems to harden this tube region.

iii) The crack propagation started in the interdendritic zones and propagates transgranularly in the austenitic region.

\section{Acknowledgements}

The authors acknowledge the financial support from SIP-IPN and Conacyt.

\section{References}

1. Davis JR. ASM specialty handbook: heat-resistant materials. Materials Park: ASM International; 1997.

2. Buchanan KG. Crystallography and morphology of MC carbides in niobium- titanium modified as-cast HP alloys. Metall Mater Trans, A Phys Metall Mater Sci. 2014;45:3373-85.

3. Soares GDA, Almeida LH, Silveira TL, May IL. Niobium additions in HP heat-resistant cast stainless steels. Mater Charact. 1992;29:387-96

4. Ribeiro EAAG, Papaleo R, Guimaraes JRC. Microstructure and Ccreep behavior of a niobium alloyed cast heat-resistant 26 pct Cr Steel. Met Trans A. 1986;17(4):691-6. http://dx.doi. org/10.1007/BF02643989.

5. Thomas CW, Stevens KJ, Ryan MJ. Microstructure and properties of alloy HP50-Nb: comparison of as Cast and service exposed materials. Mater Sci Technol. 1996;12(6):469-75. http://dx.doi. org/10.1179/mst.1996.12.6.469.

6. Alvino A, Ramires D, Tonti A, Lega D. Influence of chemical composition on microstructure and phase evolution of two HP heat resistant stainless steels after long term plant-service aging. Mater High Temp. 2014;31(1):2. http://dx.doi.org/10.1 179/0960340913Z.0000000001.

7. Buchanan KG, Kral MV. Crystallography and Morphology of niobium carbide in as-cast HP-niobium reformer tubes. Metall Mater Trans, A Phys Metall Mater Sci. 2012;43(6):1760-9. http://dx.doi.org/10.1007/s11661-011-1025-0.

8. Wiengmoon A, Chairuangsri T, Brown A, Brydson R, Edmonds DV, Pearce JTH. Microstructural and crystallographical study of carbides in 30\% Cr cast irons. Acta Mater. 2005;53(15):414354. http://dx.doi.org/10.1016/j.actamat.2005.05.019.

9. Xu Z, Ding Z, Dong L, Liang B. Characterization of M23C6 carbides precipitating at grain boundaries in $100 \mathrm{Mn} 13$ steel. 
Metall Mater A. 2016;47(10):4862-8. http://dx.doi.org/10.1007/ s11661-016-3656-7.

10. Voicu R, Andrieu E, Poquillon D, Furtado J, Lacaze J. Microstructure evolution of $\mathrm{HP} 40-\mathrm{Nb}$ alloys during aging under air at $1000^{\circ} \mathrm{C}$. Mater Charact. 2009;60(9):1020-7. http://dx.doi. org/10.1016/j.matchar.2009.04.007.

11. Mallick P, Tewary NK, Ghosh SK, Chattopadhyay PP. Effect of TMCP on microstructure and mechanical properties of 304 stainless Steel. Steel Res Int. 2018;89(8):1-7. http://dx.doi. org/10.1002/srin.201800103.

12. Saucedo-Muñoz ML, Ortiz-Mariscal A, Lopez-Hirata VM, Villegas-Cardenas JD, Soriano-Vargas O, Avila-Davila EO. Precipitation analysis of as-cast HK40 steel after isothermal aging. Int J Miner Metall Mater. 2017;24(10):1125-33. http:// dx.doi.org/10.1007/s12613-017-1503-5.

13. Padhila AF, Rios PR. Decomposition of austenite in austenitic stainless steels. ISIJ Int. 2002;42(4):325-7. http://dx.doi. org/10.2355/isijinternational.42.325.

14. Tancret F, Laigo J, Christien F, Le Gall R, Furtado J. Phase transformations in $\mathrm{Fe}-\mathrm{Ni}-\mathrm{Cr}$ heat-resistant alloys for reformer tube applications. Mater Sci Technol. 2018;34(11):1333-43. http://dx.doi.org/10.1080/02670836.2018.1449177.

15. Zhang Y, Yang J. Effect of N/C ratio on precipitation behavior of $(\mathrm{Cr}, \mathrm{Fe})_{23} \mathrm{C}_{6}$ carbide in novel cast austenitic heat-resistant steels during directional solidification. Metals. 2018;8(9):678. http://dx.doi.org/10.3390/met8090678.

16. Cueto-Rodriguez MM, Avila-Davila EO, Lopez-Hirata VM, Saucedo-Muñoz ML, Palacios-Pineda LM, Trapaga-Martinez LG, et al. Numerical and experimental analyses of the effect of heat treatments on the phase stability of inconel 792. Adv Mater Sci Eng. 2018;2018:1-16. http://dx.doi.org/10.1155/2018/4535732.

17. Andersson JO, Helander T, Höglund L, Shi PF, Sundman B. Thermo-Calc \& DICTRA, computational tools for materials science. Calphad. 2002;26(2):273-312. http://dx.doi.org/10.1016/ S0364-5916(02)00037-8.

18. American Society for Testing and Materials - ASTM. ASTM A297: standard specification for steel castings, iron-chromium and iron chromium-nickel, heat resistant, for general application. West Conshohocken: ASTM; 2004.

19. American Society for Testing and Materials - ASTM. ASTM E18: standard test method for Brinell hardness of metallic materials. West Conshohocken: ASTM; 2004.

20. American Society for Testing and Materials - ASTM. ASTM E384: standard test method for microindentation hardness of materials. West Conshohocken: ASTM; 2004.

21. Thermo-Calc Software. Thermo-Calc software [tcfe7.tdb data] version 2019a. Sweden; 2016.

22. Nishino K, Kagawa N. Structural diagram of austenitic $25 \% \mathrm{Cr}$ $20 \% \mathrm{Ni}-\mathrm{Fe}-\mathrm{C}$ type alloys. Tetsu To Hagane. 1972;58(1):107-18. http://dx.doi.org/10.2355/tetsutohagane1955.58.1_107. [in Japanese]

23. Wu XQ, Jing HM, Zheng YG, Yao ZM, Ke W, Hu ZQ. The eutectic carbides and creep rupture strength of $25 \mathrm{Cr} 20 \mathrm{Ni}$ heatresistant steel tubes centrifugally cast with different solidification conditions. Mater Sci Eng A. 2000;293(1-2):252-60. http:// dx.doi.org/10.1016/S0921-5093(00)00984-9.

24. Griffiths WD, McCartney DG. The effect of electromagnetic stirring during solidification on the structure of Al-Si alloys. Mater Sci Eng A. 1996;216(1-2):47-60. http://dx.doi.org/10.1016/09215093(96)10392-0.

25. Kishore K, Mukhopadhyay G. Failure analysis of liner plates of wet coke quenching car. J Fail. Anal. and Preven. 2019;19(3):7716. http://dx.doi.org/10.1007/s11668-019-00657-3.

26. Roy N, Raj A, Roy BN, Ray AK. Creep deformation and damage evaluation of service exposed reformer tube. Can Metall Q. 2015;54(2):205. http://dx.doi.org/10.1179/187913 9514Y.0000000175. 